\title{
APPLYING HARMONIC ANALYSIS sciendo IN THE MEASUREMENTS OF GEOMETRICAL DEVIATIONS OF THE CRANKSHAFTS - SELECTING SUPPORT CONDITIONS
}

doi:10.2478/mape-2018-0025

Date of submission of the article to the Editor: 03/2018

Date of acceptance of the article by the Editor: 06/2018

MAPE 2018, volume 1, issue 1, pp. 191-195

Dr hab. inż. Krzysztof Nozdrzykowski, prof. AM

Maritime University of Szczecin, Poland

\begin{abstract}
The article presents principles of the most suitable support conditions which enable elimination of deflections and elastic deformations of crankshafts under their self-weight. On the basis of the formulated principles sample calculations of force values of support reactions were performed. This guarantees zero value of deflections on main journals depending on the angle of rotation of the shaft, applying available programme of strength calculations Nastran FX 2010. The obtained results have been approximated with a mathematical equation applying the calculating method based on the harmonic analysis theory. Then a comparative assessment of the force diagram (the forces were obtained via strength calculations and mathematical model including so called mutual inter-correlation coefficient) was made. The obtained results of comparative analysis showed high correspondence between the compared diagrams. Presented procedures of determining the required forces ensuring elimination of deflections and elastic deformations can be applied to measurements of crankshaft geometrical deviations realized on the basis of a measuring system with, so called, flexible support of a measured object.
\end{abstract}

Keywords: harmonic analysis, geometrical deviations, elastic deflections, crankshafts, support conditions

\section{INTRODUCTION}

In machine building a commonly used method of mathematical model of shape contours of some machines, especially irregular roundness contours is a description in a form of sum of expressions of Fourier trigonometrical series (most often in a form of, so called, finite cosine transform) (Adamczak, 1998; Adamczak and Makieła, 2007). Such a description is based on the harmonic analysis theory of shape contour applicable in this case. Similar approach to the topics of shape contours' analysis has been presented in a series of publications, on determining the deviations and shape contours describing the measured roundness contours of main journals of the crankshaft set with external main journals in prisms (Adamczak, 1998; Adamczak and Makieła, 2007; Nozdrzykowski, 2013). There are also other methods used for describing shape contours, for instance, based on the wavelet analysis theory which, due to the difficulties of selecting the appropriate wavelet function, are not applicable in practice (Adamczak et al., 2010). The procedures described in the previously cited publications do not exhaust all the opportunities of use of harmonic analysis in the crankshaft geometrical deviations measurements. Such shafts are limp, prone to bending deformations. Due to this fact, depending on the support conditions they undergo elastic deformations variable with respect to the sign and value as a result of changes in the stiffness of the shaft during rotation. Elastic deformations distort measurements of geometrical values. A significant at the stage of size-and-shape control is providing a correct support for the shaft that would eliminate their bending and elastic deformations (Quan et al., 2011; Nozdrzykowski, 2013; Sun et al., 2010; Walczyk et al., 2011). 


\section{PRINCIPLES OF DETERMINING SUPPORT CONDITIONS ELIMINATING ELASTIC DEFLECTIONS OF CRANKSHAFTS}

Available programmes on strains' calculations, like Nastran FX 2010 or Inventor Professional 2017 turned out to be a great aid in the discussed research interest. After modelling a research object and making necessary calculations the programmes enable defining support conditions which ensure elimination of shaft elastic deflections (Azirjawi and Basheer, 2018; Fonte et al., 2015; Sun et al., 2010; Walczyk et al., 2011; Zhao and Cao, 2013). The studies have proved that in order to eliminate the deflections it is necessary for all main journals to be supported with the system of prism supports and at the same time for the reaction forces values at the joints of the supports and the journals to change not only at the length of the shaft but also together with the change of its angular location (Nozdrzykowski, K., 2013). Assuming the same value of the forces or no support for any of the main journals results in deflections which are impossible to eliminate. Maintaining a particular location of supports and precise realization of reaction forces values corresponding to this location allows for complete elimination of shaft deflections.

Sample results of measurement values of the forces that ensure elimination of shaft deflections realized for the discussed research object-middle-speed engine's crankshaft of the main drive of the vessel Buckau Wolf R8DV 136 have been presented in Table 1. It was a shaft of length $3630 \mathrm{~mm}$ and mass $9360 \mathrm{~N}$, with ten main journals of $149 \mathrm{~mm}$ in diameter.

Table 1

Required reaction forces values on the journals ensuring zero values of deflections on the journals at the change of angle of shaft rotation every $15^{\circ}$, calculated according to the strength calculations programme MES Nastran FH 2010

\begin{tabular}{|c|c|c|c|c|c|c|c|c|c|c|c|c|c|c|c|c|c|c|c|c|c|c|c|c|c|c|}
\hline & & \multicolumn{25}{|c|}{ Angular value [ $\left.{ }^{\circ}\right]$} \\
\hline & & 0 & 15 & 30 & 45 & 60 & 75 & 90 & 105 & 120 & 135 & 150 & 165 & 180 & 195 & 210 & 225 & 240 & 255 & 270 & 285 & 300 & 315 & 330 & 345 & 360 \\
\hline \multirow{10}{*}{ 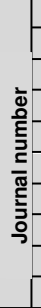 } & & 719,8 & 711,8 & 723,0 & 750,2 & 786,1 & 821,2 & 846,1 & 854,0 & 842,9 & 815,7 & 779,8 & 744,6 & 719,8 & 711,8 & 723,0 & 750,1 & 786,1 & 821,2 & 846,1 & 854,0 & 842,9 & 815,7 & 779,8 & 744,6 & 719,8 \\
\hline & & \begin{tabular}{|l|l|}
944,8 \\
\end{tabular} & 969,6 & 953,3 & 900,3 & 824,7 & 746,8 & 687,5 & 662,6 & 678,9 & 732,0 & 807,6 & 885,5 & 944,8 & 969,6 & 953,3 & 900,3 & 824,7 & 746,8 & 687,5 & 662,6 & 678,9 & 732,0 & 807,6 & 885,5 & 944,8 \\
\hline & 5 & 793,6 & 737,8 & 734,8 & 785,4 & 876,1 & 982,6 & 1076,4 & 1132,3 & 1135,3 & 1084,7 & 993,9 & 887,4 & 793,6 & 737,8 & 734,8 & 785,4 & 876,1 & 982,6 & 1076,4 & \begin{tabular}{|l}
1132,3 \\
\end{tabular} & 1135,3 & 1084,7 & و993,9 & 887,4 & 793,6 \\
\hline & 4 & 1105,9 & 1184,2 & 1200,0 & 1149,1 & 1045,1 & 916,0 & 796,3 & 718,0 & 702,2 & 753,1 & 857,0 & \begin{tabular}{|l}
986,1 \\
\end{tabular} & 1105,9 & 1184,2 & 1200,0 & 1149,1 & 1045,1 & 916,0 & 796,3 & 718,0 & 702,2 & 753,1 & 857,0 & 986,1 & 1105,9 \\
\hline & 5 & $\begin{array}{r}757,0 \\
\end{array}$ & 699,3 & 698,9 & 756,0 & 855,1 & \begin{tabular}{|l|}
969,8 \\
\end{tabular} & 1069,3 & 1127,0 & 1127,4 & 1070,4 & 971,3 & 856,6 & 757,0 & 699,3 & \begin{tabular}{|l|l|}
698,9 \\
\end{tabular} & 756,0 & 855,1 & 969,8 & 1069,3 & 1127,0 & 1127.4 & 1070,4 & 971,3 & 856,6 & 757,0 \\
\hline & 6 & 1024,4 & 1061,3 & 1046,9 & 985,2 & 892,6 & 793,9 & 715,7 & 678,8 & 693,2 & 754,9 & 847,5 & 946,1 & 1024,4 & 1061,3 & 1046,9 & 985,2 & 892,6 & 793,9 & 715,7 & 678,8 & 693,2 & 754,9 & 847,5 & 946,1 & 1024,4 \\
\hline & , & 760,3 & 702,5 & 701,7 & 758,1 & 856,7 & 971,0 & 1070,4 & 1128,2 & 1129,0 & 1072,5 & 973,9 & 859,7 & 760,3 & 702,5 & 701,7 & 758,1 & 856,7 & 971,0 & 1070,4 & $\begin{array}{l}1128,2 \\
\end{array}$ & 1129,0 & 1072,5 & 973,9 & 859,7 & 760,3 \\
\hline & 8 & 1088,2 & 1165,8 & 1183,6 & \begin{tabular}{|l|}
1136,6 \\
\end{tabular} & 1037,6 & 913,0 & 796,3 & 718,7 & 700,9 & 747,9 & 846,9 & 971,5 & 1088,2 & 1165,8 & \begin{tabular}{|l|l|}
1183,5 \\
\end{tabular} & 1136,6 & 1037,6 & 913,0 & 796,3 & 718,7 & 700,9 & 747,9 & 846,9 & 971,5 & 1088,2 \\
\hline & 9 & 880,1 & 828,8 & 816,9 & 847,6 & 912,7 & 994,8 & 1071,8 & 1123,1 & 1135,0 & 1104,3 & 1039,2 & 957,1 & 880,1 & 828,8 & 816,9 & 847,6 & 912,7 & 994,8 & 1071,8 & 1123,1 & 1135,0 & 1104,3 & 1039,2 & 957,1 & 880,1 \\
\hline & 10 & 584,2 & 597,2 & 599,3 & 589,9 & 571,5 & 549,0 & 528,66 & 515,6 & 513,5 & 522,9 & 541,3 & \begin{tabular}{|l|l|}
563,7 \\
\end{tabular} & 584,2 & 597,2 & 599,3 & 589,9 & 571,5 & 549,0 & 528,6 & 515,6 & $\begin{array}{r}513,5 \\
\end{array}$ & 522,9 & 541,3 & $\begin{array}{l}563,7 \\
\end{array}$ & 584,2 \\
\hline
\end{tabular}

Table 1 presents required reaction forces values on the journals ensuring zero values of deflections on the journals at the change of angle of shaft rotation every $15^{\circ}$, calculated according to the strength calculations programme MES Nastran FH 2010. Yet, a graphic interpretation is a better form of presenting the results. The analysis of such a presentation of the results has shown that the discussed distribution of forces ensuring zero values of deflections on the particular journals expressed in a polar coordinate system creates a picture of a regular ellipse, what corresponds to a function similar to cosine in the cartesian coordinate system. The criteria of harmonic analysis are applicable to the mathematical model of such function (Adamczak, 1998; Nozdrzykowski, 2013). According to the harmonic analysis a second harmonic compound expressing to what degree the contour is oval is the main compound of the description of mathematical contour. It is proved by the calculations made in Matlab environment (Table 2). Table 2 shows the values of first twelve harmonic compounds of the function which represents mathematical model of reaction forces changes ensuring zero values of deflections on particular main journals. Calculations of harmonic compounds have been realized on the basis of a function relation described as follows:

$$
R(\varphi)=R_{0}+\sum_{n=1}^{k} C_{R n} \cos n\left(\varphi-\varphi_{R n}\right)
$$


where:

$R_{0}$ - mean value of calculated reaction force,

$C_{R n}$ - amplitude of consecutive $n$ - harmonics of mathematical model of reaction forces,

$\varphi_{R n}$ - phase shift of consecutive $n$ - harmonics of mathematical model of reaction forces or corresponding to it:

$$
R(\varphi)=R_{0}+\sum_{n=1}^{k} A_{R n} \cos n \varphi+\sum_{n=1}^{k} B_{R n} \sin n \varphi
$$

where:

$A_{R n}, B_{R n}$ - amplitudes' compounds of consecutive $n$ - harmonics of mathematical model of reaction forces.

Table 2

Values of first twelve harmonic compounds of the function which represents mathematical model of reaction forces changes ensuring zero values of deflections on particular main journals.

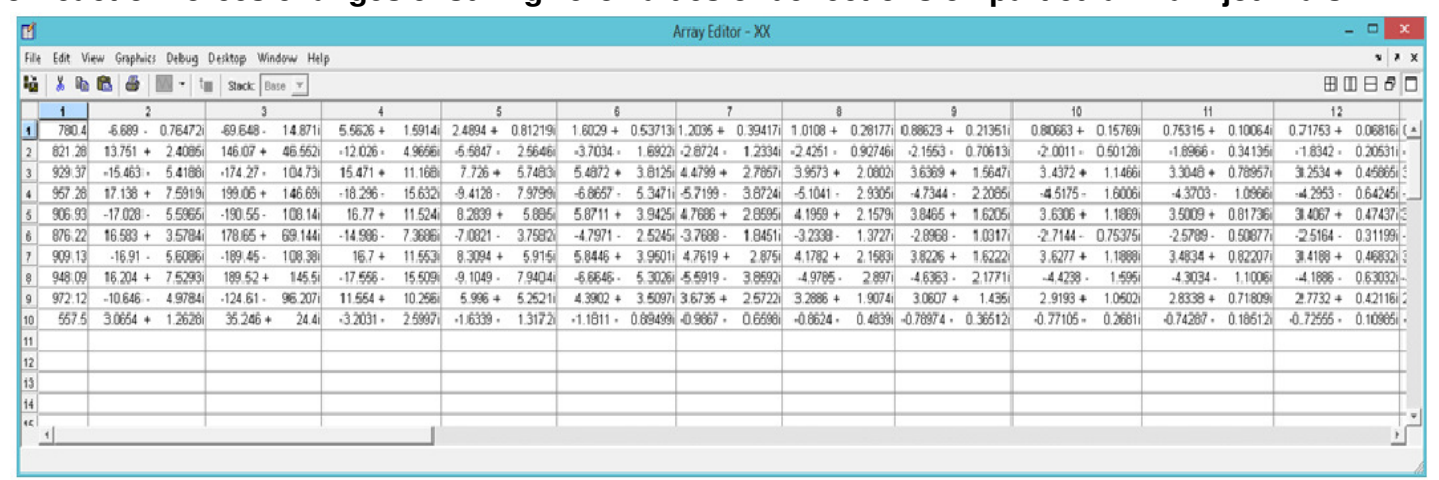

A comparative assessment of the diagram of forces obtained via strength calculations and mathematical model expressed in a form of Fourier trigonometrical series has been made. The comparative assessment has been made by calculating mutual inter-correlation coefficient, described as: (Janecki et al., 2004; Janecki et al., 2008; Nozdrzykowski, 2013; Nozdrzykowski and Janecki, 2014):

$$
\rho\left(\gamma_{\varphi}\right)=\frac{2 \int_{0}^{2 \pi} r_{1}(\varphi) r_{2}\left(\varphi+\gamma_{\varphi}\right) \mathrm{d} \varphi}{\int_{0}^{2 \pi} r_{1}(\varphi)^{2} \mathrm{~d} \varphi+\int_{0}^{2 \pi} r_{2}(\varphi)^{2} \mathrm{~d} \varphi}
$$

where:

$r_{1}(\varphi)$ - diagram obtained via strength calculations,

$r_{2}(\varphi)$ - diagram obtained via mathematical model,

$\gamma_{\varphi}$ - phase shift between the compared diagrams.

Table 3

Calculated values of mutual inter-correlation coefficients for the studied journals

\begin{tabular}{|c|c|}
\hline Journal number & Mutual inter-correlation coefficient $\boldsymbol{\rho}(\boldsymbol{\varphi})$ \\
\hline 1 & 0.9578 \\
\hline 2 & 0.9568 \\
\hline 3 & 0.9548 \\
\hline 4 & 0.9543 \\
\hline 5 & 0.9549 \\
\hline 6 & 0.9562 \\
\hline 7 & 0.9549 \\
\hline 8 & 0.9542 \\
\hline 9 & 0.9542 \\
\hline 10 & 0.9544 \\
\hline
\end{tabular}


Table 3 presents calculated values of mutual inter-correlation coefficients for the studied system of journals. The value of mutual inter-correlation coefficients for the journals equalled from 0.9542 to 0.9578 , what, according to the assessment scale for determining the correlation degree adopted by J. P. Guilford, corresponds to a very high correlation between the compared diagrams. In line with this assessment scale the degree of correlation between the analysed characteristics of the diagrams is certain - Fig. 1.

a)

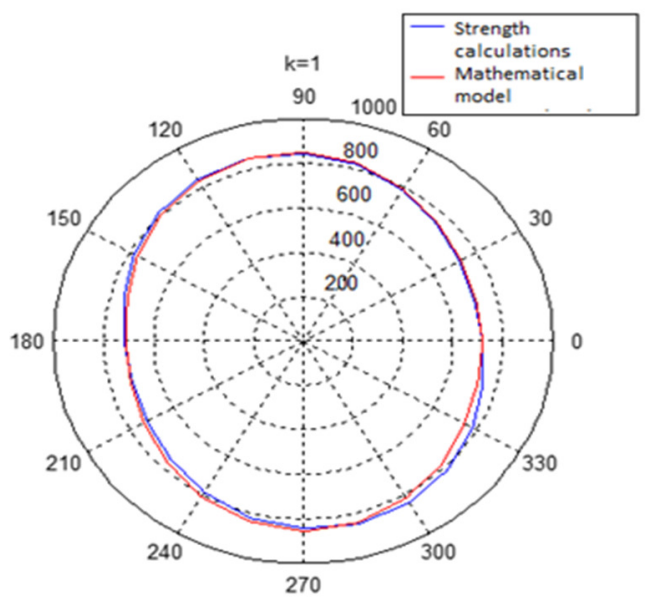

b)

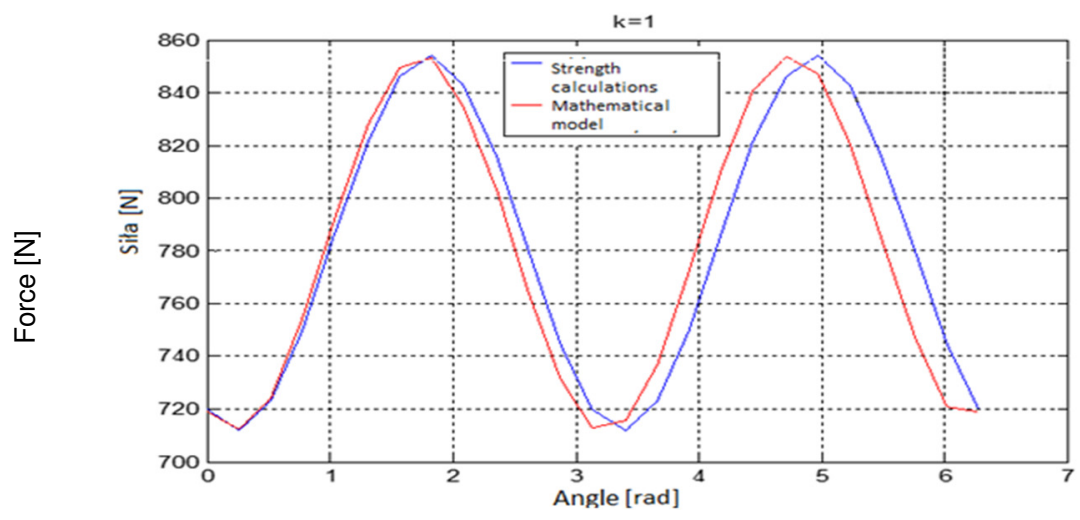

Fig. 1. Distribution of forces on the whole range of shaft rotation $0 \div 360^{\circ}$ ensuring zero values of deflections on journal No 1 (counting from the side of the timing wheel), in the coordinate system: a) polar, b) cartesian

Figure 1 presents, both in polar and cartesian coordinate system, the distribution of forces obtained as a result of strength calculations and mathematical model on the whole range of shaft rotation $0 \div 360^{\circ}$ ensuring zero values of deflections for the chosen main journal (journal No 1 , counting from the side of the timing wheel).

\section{CONCLUSIONS}

Presented procedures of determining the required reaction forces ensuring elimination of elastic deflections of the shaft found practical application during crankshaft geometrical deviations' measurements realized with the use of a measuring system with so called flexible shaft support (Nozdrzykowski, 2013), developed in Maritime University of Szczecin. In the proposed solution of the measuring system the role of elements compensating possible elastic deflections is played by flexible supports placed in the middle part of the shaft. These supports, whose number and distribution depends on number and distribution of main journals, realize given variables of reaction forces at the joints of supports' heads and journals. Given values 
of reaction forces are first of all calculated with the use of a programme for strength calculations, and then they are expressed as a mathematical model in a form of Fourier trigonometrical series. Such a model enables continuous monitoring of the work of precise controllable valves by dint of which the inlet of flexible lift-off supports supply medium is adjusted.

\section{REFERENCES}

Adamczak, S. (1998). Odniesieniowe metody pomiaru zarysów okrągłości części maszyn. Monografie, Studia, Rozprawy. Politechnika Świętokrzyska, Kielce.

Adamczak, S. and Makieła, W. (2007). Metrologia w Budowie Maszyn, zadania z rozwiązaniami. Wydanie drugie zmienione. Warszawa: WNT.

Adamczak, S., Makieła, M. and Stępień, K. (2010). Investigating advantages and disadvantages of the analysis of a geometrical surface structure with the use of Fourier and wavelet transform. Metrology and Measurement Systems, vol. XVII, No. 2.

Azirjawi, A, and Basheer, S.K. (2018). New design solution for crankshaft. Proceedings of the asme international mechanical engineering congress and exposition, 2017, vol 2.

Fonte, M., Duarte, P., Anes, V., Freitas, M. and Reis, L. (2015). On the assessment of fatigue life of marine diesel engine crankshafts. Engineering failure analysis, vol. 56, p. 51-57.

Janecki, D., Adamczak, S. and Stępień, K. (2008). An analysis of the applicability of the cross-correlation function to the comparision of cylindrical profiles. Pomiary Automatyka Kontrola, Vol. 54, No. 5, pp. 237-243.

Janecki, D., Adamczak, S. and Stępień, K. (2004). Analysis of the accuracy of reference cylindricity measurements using the normalized cross correlation function. Science report, Project PL-127, CEEPUS Kielce University of technology, pp. 57-66.

Nozdrzykowski, K. (2013). Metodyka pomiarów geometrycznych odchyłek powierzchni walcowych wielkogabarytowych elementów maszyn na przykładzie wałów korbowych silników okrętowych. Wydawnictwo Naukowe Akademii Morskiej w Szczecinie.

Nozdrzykowski, K. and Janecki, D. (2014). Comparative studies of reference measurements of cylindrical surface roundness profiles of large machine components. Metrology and Measurement System, vol. XXI, No. 1, pp. 67- 76.

Sun, J., Wang, J. and Gui, C. (2010). Whole crankshaft beam-element finite-element method for calculating crankshaft deformation and bearing load of an engine. Proceedings of the institution of mechanical engineers part j-journal of engineering tribology, vol. 224, p. 299-303.

Quan, W., Wei, J., Zhao, YW., Sun, LH. and Bianl, XY. (2011). Development of an Automatic Optical Measurement System for Engine Crankshaft. 2011 International Conference on Computational Science and Applications, p. 68-75.

Walczyk, W., Milenin, A. and Pietrzyk, M. (2011). Computer Aided Design of New Forging Technology for Crank Shafts. Steel research international, vol. 82, p. 187-194.

Zhao, Y. and Cao, SQ. (2013). Modal Analysis of Large Marine Crankshaft. Frontiers of manufacturing and design science III, pts 1 and 2, vol. 271-272, p. 1022-1026. 